\title{
Case Report: Normocalcemic Hyperparathyroidism
}

\author{
Hemn Muhammed Mustafa1, Mohamed Al Shekhani2, Bnar Jamal³ \\ ${ }^{1}$ FIBMS (med), Department of Medicine, Iraqi Board in Internal Medicine, Sulaymaniyah General Teaching \\ Hospital, Sulaymaniyah, Iraq \\ ${ }^{2}$ Department of Medicine, Sulaymaniyah Faculty of Medical Sciences, School of Medicine, University of \\ Sulaymaniyah, Arabic Board in Internal Medicine, Sulaymaniyah, Iraq \\ ${ }^{3}$ Internal Medicine House Officer, Iraqi Board of Internal Medicine Candidate, Sulaymaniyah General Teaching \\ Hospital, Sulaymaniyah, Iraq \\ Email: shaikhanimohammad@googlemail.com
}

Received 5 March 2014; revised 4 April 2014; accepted 2 May 2014

Copyright (C) 2014 by authors and Scientific Research Publishing Inc.

This work is licensed under the Creative Commons Attribution International License (CC BY). http://creativecommons.org/licenses/by/4.0/

(C) (i) Open Access

\begin{abstract}
A case of normocalcemic hyperparathyroidism is diagnosed basing on the clinical manifestations \& laborotary investigation supported by finding of unilateral parathyroid adenoma on imaging studies and the patient was referred for surgical exploration for the parathyroid adenoma.
\end{abstract}

\section{Keywords}

Normocacemic Hyperparathyoidismm, Vitamin D Deficiency, Osteopenia

\section{The Case Report}

A 38-year-old house wife from Sulaimanya city was admitted at 5th April 2013. Her chief complaint was bilateral thigh pain for 4 months. The condition started 4 months ago as continuous dull pain in both thigh initially mild progress to moderate-sever pain last month, increased during exertion \& standing, became better by rest \& analgesia, not associated weakness, parasthesia or numbness; no swelling or tenderness in her joints with good movement no stiffness. After 1 month the same type \& character of pain involved upper \& lower back \& chest wall but it was milder in severity. She was seen 1 time by orthopedics who prescribed analgesia after few investigations. She was continuously taking analgesia from paramedics. During the last few months, intermittent left loin sever colicky pain lasting 1 - 2 hour, radiating toward umbilicus, subside spontaneously or by analgesia started, but no fever, dysuria, hematuria, frequency, or dribbling occurred. She was seen by urologist who prescribed treatment for renal stone without admission to hospital. Eight years ago she had renal stone and extracor- 
poreal shock was lithotripsy (ESWEL) which was done without complication. In the last 2 months she had frequent attacks of generalized skin itching, especially in the face, palm, sole; mostly at day, they increase by hot weather, lasting a few hours and resolve spontaneously, not associated with skin lesions, no fever, weight loss and with good appetite. She has no chest pain, cough, dyspnea, wheeze, no palpitation, exertional dyspnea, or thopnea, no oral lesion, heart burn, malena, tenismus, no head ache, loss of consciousness or focal neurological deficits. There is no history of the same condition before. Thirteen years ago she had surgery for ovarian cyst, with 2 days stay in the hospital without complication. There was no history of blood transfusions. Menarche was at 13 years of age with irregular menses, but no menorhagia. Infertile despite regular intercourse and for a few years with regular visits to gynecologist, she was given many courses of hormonal therapy. No history of chronic illness. Father and mother have no disease. She has 3 sisters, who are all married and have children. Her husband is a building worker with good health. There are no extramarital relations, no contact with sick people and no animal contact. She didn't smoke or drink alcohol. She has no traveling history.

On physical examination, vital signs were normal with normal body mass index. Middle aged female with good body build, not dyspnic, look healthy, she is anxious but cooperative, conscious \& oriented to time, place \& person, dysarthria from childhood. She has no abnormal movement, no muscle wasting or cyanosis, no clubbing or any nail change like koilonychia, paronychia, lukonychia or splinter hemorrhage, no any skin lesion, no joint tenderness with good range of movement. Her hair is of average texture, scalp without lesion, normocephalic atraumatic. Eyes had normal visual field with intact movements, pink conjunctiva, sclera white, pupil round regular, equally reacting to light. The fundus was normal with sharp disc margins. The ears were externally normal with no gross abnormalities and both canals were clear. The nose was with no gross abnormalities and normal septum and there was no tenderness over paranasal sinuses. The throat and oral cavity were normal. There was no any visible mass or scar in the neck. There was tenderness in submandibular region but on any lymph node or thyroid enlargement. The JVP was not obvious. There was normal shape chest with noscars and there was a resonant chest percussion and vesicular breath sound. The heart was with visible apex beat and palpable in 5th intercostal space. There was normal S1, S2 and no added sound. There was no radio-radial, or radio-femoral delay. The Peripheral pulses were present and normal. There were no palpable axillary lymphnodes. The abdomen was flat, symmetrical, no scar and no dilated vein, moving with respiration. The abdomen was soft to palpation with nopalpable mass or organomegally (liver span $6 \mathrm{~cm}$ ), positive bowel sound and no bruit. There was no skin lesion, dilated vein, muscle wasting or swelling and no joint redness and swelling. There was tenderness of both thigh, spine and chest wall; but no other joints tenderness, crepitus or effusion. There was no joint stiffness, good rang of movement, but there was coarse crepitus and mild pain during movement of right knee. The complete blood picture was normal with EsR of $6 \mathrm{~mm} / \mathrm{h}$.FBS 155, renal functions normal, electrolytes normal except Serun phosphorus of $1.3 \mathrm{mgm} / \mathrm{dl}$ \& LFTs normal except very high serum alkhaline phosphatase of 2160 IU/L, Gama GT 22 U/L, 25-0H Vit D3 $2.6 \mathrm{ng} / \mathrm{ml} \& 9.98 \mathrm{ng} / \mathrm{ml}$ at second occasion (N:47-144). Celiac serology was negative; serum parathyroid hormone level was very high 452,460 Pg/ml (N:4-57.1); GUE was normal and urinary electrolyte level was normal. Abd ultrasound revealed only 2 right sided upper pole small stones of 5 mms Neck Doppler ultraouns exam revealed well-defined elongated hypoechoic mass of $29 \times 20 \times 14$ mms posterior to the right thyroid lobe suggestive of parathyroid adenoma showing significantly low \& high resistance arterial flow. Dexa bone densiometry scan revealed osteopenia. Thyroid function tests were normal, and ANA \& Anti DS-DNA levels were normal. CPK level was normal. Latex, brucella \& CRP were normal. Radiographic bone survery was normal except for osteopenia.

The differential diagnosis was normal calcemic primary hyperparathyroidism with concomitant vitamin D deficiency \& Osteomalacia-induced tertiary hyperparathyroidism.

Analgesia, one alfa tablets, Anti-histamin \& levocetrizine was prescribed \& surgical consultation was done.

After 3 months of the above treatment investigations revealed the following:

$\mathrm{S}$ Calcium $10.04 \mathrm{mgm} / \mathrm{dl}$, magnesium $1.7 \mathrm{mgm} / \mathrm{dl}$, phosphorous $2.85 \mathrm{mgm} / \mathrm{dl}$.

Vitamine D3 level 6 ng/ml (N 30 - 50) \& Serum PTH still high 647 Pg/ml.

The patient was scheduled for parathyroidectomy.

\section{Discussion}

Occasionally, patients with primary hyperparathyroidism have normal total and ionized calcium concentrations (normocalcemic primary hyperparathyroidism). These patients typically come to medical attention in the setting 
of an evaluation for low bone mineral density. In these cases, it may be difficult to distinguish secondary hyperparathyroidism from early primary hyperparathyroidism because the biochemical findings may be similar [1] [2]. Secondary hyperparathyroidism may occur in patients with renal failure and impaired calcitriol production, as well as in individuals with inadequate calcium intake or absorption, as can occur with vitamin D deficiency or with GI diseases causing malabsorption [3] [4]. Assessment of renal function (serum creatinine), (Vit.D3), and (urinary calcium excretion) may help differentiate normocalcemic primary from secondary hyperparathyroidism. Further assessment and work-up for specific gastrointestinal disorders is generally undertaken only when the clinical suspicion is high. Some patients may have more than one condition leading to increased PTH secretion. Co-existing primary hyperparathyroidism and vitamin D deficiency is not uncommon. When this occurs, the serum calcium level in the primary hyperparathyroid may be reduced (into the normal range in some cases) due to vitamin D deficiency [5] [6]. Increasingly, patients undergoing evaluation for low bone density or other conditions may have elevated PTH in the absence of hypercalcemia. An international panel of experts recognized a new phenotype of primary hyperparathyroidism in which PTH levels are elevated but serum calcium is normal. In order to make this diagnosis, certain conditions must be met. In particular, all secondary causes for hyperparathyroidism must be ruled out, and ionized calcium levels should be normal [6]. The most common explanation for the finding of an elevated PTH and normal serum calcium remains concomitant hypercalcemic PHPT and vitamin D deficiency. Due to the significant prevalence of vitamin D insufficiency in individuals with PHPT, the third International Workshop recommends measuring Vitamin D3 in all patients with PHPT and repleting those with low levels (defined as $\leq 20 \mathrm{ng} / \mathrm{mL}$ [50 nmol/L]) prior to making any management decisions [7]. Specific repletion recommendations are not available from clinical trial data. Until such information becomes available, cautiously repleting vitamin D in patients with underlying hyperparathyroidism is recommended since worsening hypercalcemia and hypercalciuria have been reported [8]-[14].

\section{References}

[1] http://www.uptodate.com

[2] Díaz-Soto, G., Julián, M.T. and Puig-Domingo, M. (2012) Normocalcemic Primary Hyperparathyroidism: A Newly Emerging Disease Needing Therapeutic Intervention. Hormones (Athens), 11, 390-396. http://dx.doi.org/10.14310/horm.2002.1370

[3] Koumakis, E., Souberbielle, J.C., Sarfati, E., Meunier, M., Maury, E., Gallimard, E., et al. (2013) Bone Mineral Density Evolution after Successful Parathyroidectomy in Patients with Normocalcemic Primary Hyperparathyroidism. The Journal of Clinical Endocrinology and Metabolism, 98, 3213-3220. http://dx.doi.org/10.1210/jc.2013-1518

[4] Gupta, V. (2013) Normocalcemic Primary Hyperparathyroidism in a Patient with Severe Osteoporosis Receiving Teriparatide. Indian Journal of Endocrinology and Metabolism, 17, 336-338. http://dx.doi.org/10.4103/2230-8210.109664

[5] Cusano, N.E., Maalouf, N.M., Wang, P.Y., Zhang, C., Cremers, S.C., Haney, E.M., et al. (2013) Normocalcemic Hyperparathyroidism and Hypoparathyroidism in Two Community-Based Nonreferral Populations. The Journal of Clinical Endocrinology and Metabolism, 98, 2734-2741. http://dx.doi.org/10.1210/jc.2013-1300

[6] Martínez Díaz-Guerra, G., Jódar Gimeno, E., Reyes García, R., Gómez Sáez, J.M., Muñoz-Torres, M., et al. (2013) Normocalcemic Primary Hyperparathyroidism: Recommendations for Management and Follow-up. Endocrinological Nutrition, 60, e1-e6.

[7] Bilezikian, J.P. and Silverberg, S. (2010) Normocalcemic Primary Hyperparathyroidism. Arq Bras Endocrinological Metabology, 54, 106-109. http://dx.doi.org/10.1590/S0004-27302010000200004

[8] Tachibana, S., Yokoi, T., Sato, S., Yanase, T. and Yamashita, H. (2013) Surgically Proven Normocalcemic Primary Hyperparathyroidism: Speculation of the Possible Role of Estrogen in the Etiology of This Disease in Premenopausal Women. Internal Medicine, 52, 781-785. http://dx.doi.org/10.2169/internalmedicine.52.8496

[9] Cusano, N.E., Silverberg, S.J. and Bilezikian, J.P. (2013) Normocalcemic Primary Hyperparathyroidism. Journal of Clinical Densitometry, 16, 33-39. http://dx.doi.org/10.1016/j.jocd.2012.12.001

[10] Lewiecki, E.M. and Miller, P.D. (2013) Skeletal Effects of Primary Hyperparathyroidism: Bone Mineral Density and Fracture Risk. Journal of Clinical Densitometry, 16, 28-32. http://dx.doi.org/10.1016/j.jocd.2012.11.013

[11] Grønli, O. and Wynn, R. (2013) Normocalcemic Hyperparathyroidism and Treatment Resistant Depression. Psychosomatics, 54, 493-497. http://dx.doi.org/10.1016/j.psym.2012.10.008

[12] Misiorowski, W. and Zgliczyński, W. (2012) Prevalence of Primary Hyperparathyroidism among Patients with Low Bone Mass. Advances in Medical Sciences, 57, 308-313. http://dx.doi.org/10.2478/v10039-012-0062-2

[13] Saliba, W., Lavi, I., Rennert, H.S. and Rennert, G. (2013) The Evaluation of Vitamin D Status in Normocalcemic Prima- 
ry Hyperparathyroidism. European Journal of Internal Medicine, 24, e8. http://dx.doi.org/10.1016/j.ejim.2012.05.014

[14] Martínez Díaz-Guerra, G., Guadalix Iglesias, S. and Hawkins Carranza, F. (2013) Normocalcemic Primary Hyperparathyroidism: A Growing Problem. Medicina Clínica (Barc), 141, 125-129.

http://dx.doi.org/10.1016/j.medcli.2012.09.025 